\title{
The Post Keynesian alternative to inflation targeting
}

\author{
Angel Asensio *** and Mark Hayes *****
}

\begin{abstract}
While mainstream policies may be beyond improvement in the enchanted optimizable world, Post Keynesians have to manage without a magic wand in our uncertain world. We discuss the alternative policies proposed in the recent Post Keynesian literature and argue that control of interest rates is too imperfect for such policies to be feasible in general, although they provide useful guidelines and may be successful in favourable circumstances. Consequently, the question of credibility is irrelevant, if this means whether policy-makers will honour their commitment to an unfeasible ideal target. The right question is whether policy is convincing enough to make the conventional state of expectation (and the related interest rate) consistent with full employment. It is all a matter of confidence. The basic principles involved in such an approach to monetary policy are discussed.

JEL classifications: EI2, E\$2
\end{abstract}

Keywords: interest rate rule, convention, uncertainty, monetary policy

* CEPN, University of Paris I3.

** Homerton College, Cambridge.

*** This paper was prepared for the workshop IInflation targeting: Is there a credible alternative?, organised by the Post Keynesian Economics Study Group at Balliol College, Oxford, April 2008. The authors are grateful to Vicky Chick, Giuseppe Fontana, Malcolm Sawyer, Geoff Tily and Eckhard Hein for helpful comments.

Correspondence Address:

Prof. Angel Asensio, CEPN, U.F.R. sciences économiques, Université Paris I3, 99 avenue J.-B. Clément, 93430 Villetaneuse, France, e-mail: asensio.angel@univ-parisı3.fr.

Received o8 September 2008, accepted I6 February 2009

(C) INTERVENTION 6 (I), 2009, 65-79 
"We must remind ourselves that there may be several slips between the cup and the lip.« J.M. Keynes, The General Theory

\section{Introduction}

Old Keynesian ‘ economic policy recipes have been discarded as no longer credible because they were based upon the degenerate `hydraulic Keynesian` machine, in which the achievement of full employment was an elementary matter of shifting the IS and/or LM curve(s) appropriately. The consistent mainstream response has been to develop the idea that rational agents would not make systematic errors in forming their expectations within such a simple economic machine. And here we are: inflation targeting` (let us call it `Non Inflationary Stabilizing Policy`) has become the optimal policy response to stochastic disturbances of dynamically stable and therefore predictable and optimizable systems, characterised by the new standard form of modelling, the dynamic stochastic general equilibrium model (DSGE, see Benassy 2007 for a recent stylised version).

Echoing the reassessment of monetary and fiscal policy by Arestis and Sawyer (2003a, $2003 \mathrm{~b}$ and $2003 \mathrm{C}$ ), a process of collective reflection has recently been seeking to conceive a Post Keynesian alternative to mainstream economic policy (Fontana/Palacio-Vera 2007, Setterfield 2007a, Setterfield/Lima 2008, Atesoglu 2007, Palley 2006). Some authors suggest making inflation targeting more countercyclical, so as to have stronger real effects over the cycle and growth path, while others argue for a policy aimed at maintaining the interest rate at a low level. More ambitious proposals aim at designing an integrated monetaryfiscal policy mix (Arestis/Sawyer 2003b, Câmara Neto/Vernengo 2004, Setterfield 2007b), sometimes including income policy (Hein/Stockhammer 2007). For example, Arestis and Sawyer (2003b) suggest a ‘fiscal Taylor rule`so as to compensate for the weakness of monetary policy (see also Setterfield 2007b).

Although they contain stimulating ideas and provide useful guidelines, these contributions overlook the fact that the central bank's control over interest rates is very imperfect, because of the shifting nature of liquidity preference and the demand for money, and because of the undesirable consequences that might result from interest rates adjustments. There is some residual 'hydraulic Keynesianism` in the assumption that the central bank can freely set the rate of interest at the ideal level. If it was possible for economic policies to ensure full employment and price stability by means of a set of simple - or even sophisticated - rules, any Post Keynesian policy mix would, at best, do as well as the mainstream's optimal one. The mainstream will always reign supreme in their enchanted soptimizable world. Post Keynesians must resign themselves to managing without a magic wand in the uncertain and imperfectly malleable real world.

Section 2 considers first the methodological roots of the Post Keynesian critique of mainstream policy recommendations and the need for an alternative. Section 3 discusses the alternative interest rules mentioned above, along with the problem of feasibility. This sec- 
tion also outlines some general principles for improving the effectiveness of the Post Keynesian macroeconomic policies. Section 4 concludes that a Post Keynesian ontology has profound implications for the kind of policy that is likely to succeed. The mainstream has once again fallen into a hydraulic trap.

\section{Economic policy as a smagic wand}

The mainstream view, expressed in macroeconomic terms, is that insufficient aggregate demand in the goods market or, equivalently, an excess of planned saving, is a state of disequilibrium, for competitive forces would trigger a decrease in the rate of interest which simultaneously would clear both the market for goods and the market for bonds. In the monetary version of the theory, where the money market is included, the real balance or >Pigou effect and the so-called `Keynes effect` contribute to the support of aggregate demand as well.

Keynes by contrast stated that, in the face of uncertainty, the tendency of a fall in aggregate demand to reduce interest rates may encounter various obstacles. First, it depends on the behaviour of the banking system: if the money supply decreases along with the demand for money (as in the endogenous money literature), the rate of interest will remain unchanged. Secondly, it may be that the depressive forces harm the state of confidence so that people try to increase the share of liquid assets in their portfolio (this shift in liquidity-preference would limit or inhibit both the Keynes and Pigou effects, for money demand in this case does not fall as much, which limits the Keynes effect, and reduces the excess of real balances, compared to money demand, which limits the Pigou effect). Furthermore, the worsening business climate could deter investment projects despite any reduction in the interest rate. Thus, without even considering possible destabilizing forces (e.g. the effects of changes in money-wages pointed out in Keynes 1936: Chapter 19, or the debt-deflation effect in Fisher 1933), it appears that, in the presence of uncertainty, the stabilizing forces themselves may fail.

According to the mainstream, as competitive forces are assumed to drive the system to a ^natural anchor, macroeconomic policy can at best help to stabilize the economy when rigidities delay the adjustment process. In such a context, automatic monetary and fiscal rules can be formulated, since they aim merely to offset deviations from the anchor (the snaturak value). As such governance principles work symbiotically with the mainstream approach (Dixit/Lambertini 2003), they stabilize the macroeconomic system perfectly. The same rules, however, have severe drawbacks if they are implemented in a Keynesian model of the economy (Asensio 2006, 2007a and 2007b, Atesoglu/Smithin 2006, Palley 2007, Sawyer 2007, Setterfield/Lima 2008). As Asensio pointed out, in the absence of a spontaneous return towards full employment, a depressed level of unemployment becomes the macroeconomic policy target as soon as it comes to be considered the snatural rate, with the result that the policy mix `symbiotically ‘ anchors the system away from full employment. The persistence of a high 'natural rate of unemployment in that case results from the policy, while it is held by the $>$ New Consensus macroeconomics to be the result of real wage rigidity. This line of 
argument suggests a kind of unemployment trap, which the mainstream calls hysteresis': when the stabilization of a negative shock works only partially, unemployment increases, and policy-makers then take the actual unemployment rate to be the new 'natural rate.

Similar drawbacks may arise with respect to tensions over income distribution. Inflation depends on factors affecting distribution (the mark-up, wages pressure relative to productivity gains, or taxes on profits ${ }^{2}$ ). These factors may affect the unemployment rate indirectly through the monetary policy reaction they trigger. Whatever may be the proximate causes of inflationary pressures, the central bank can always restrict the actual rate of inflation by increasing the interest rate and the level of unemployment in such a way that the pressures fade. Indeed, higher interest rates increase unemployment and reduce the workers' ability to negotiate money-wage increases in proportion to the increase in the price index, therefore reducing inflationary pressures. Higher interest rates and lower economic activity could temper other sources of cost-push inflation as well (there is little doubt that the longterm interest rate can always be increased, the problem is in reducing it). Inflation is always a monetary phenomenon in the trivial sense that it means higher money prices of goods and services, but while mainstream economics blames irresponsible or lax fiscal and monetary policies, the Post Keynesian approach emphasises the dilemma stemming from the distributive tensions: to preserve the value of money and assume higher unemployment, or to preserve employment and let inflation develop. The mainstream holds moreover that reducing monetary inflation has no permanent cost in terms of unemployment, whereas Post Keynesians claim that it does, insofar as persistent distributive tensions induce the monetary authorities to adopt an incomes policy of fear (Davidson 2006). ${ }^{3}$

This argument suggests that New Consensus macroeconomic policy is inadequate, or worse, within a Keynesian understanding of the world; the mainstream attempt to wave a magic wand leads to erroneous targets and the misuse of policy instruments. The Post Keynesian perspective demands an alternative approach to policy.

\section{Getting rid of the wand}

\section{I Activist and 'parking it< monetary rules}

Two kinds of Post Keynesian alternatives to inflation targeting have been put forward recently (Rochon/Setterfield 2007a): sparking it‘ rules and ractivist‘ rules. The advocates of

I On hysteresis, see the Minisymposium in the Journal of Post Keynesian Economics I5(3), 1993.

2 Taxes paid by firms, given the mark up and unit labour cost, reduce distributable profits or are shifted onto consumers and workers. Taxes paid by workers also may induce wage pressures aiming at preserving the purchasing power of the money-wage. In an open economy, the prices of oil and imported intermediate goods should also be taken into account as an example of international distributive conflict. Notice that even the use of seignorage in an inflationary environment as an alternative to taxation is an example of distributive conflict.

3 See Palley (I996 and 200I) for an empirical discussion. 
activist rules consider that authorities should adjust the interest rate more actively than recommended in the mainstream, so as to take advantage of the real effects of monetary policy. >Parking it rules on the other hand are a response both to the idea that »inflation is first and foremost the result of conflict over the distribution of income (Rochon/Setterfield 2007b: 8), so that monetary policy is not the appropriate tool to fight inflation, and to the idea that the wisdom of active monetary policy is questionable, owing to the many uncertainties in the transmission mechanism (Wray 2007, Bateman 2003). >Parking it rules are therefore to be understood as full policy-mix proposals (Hein/Stockhammer 2007) based on the following principles:

- fiscal policy works countercyclically;

- incomes policy aims at fighting inflation;

- monetary policy parks the interest rate with an explicit distributional objective.

The philosophy of the Post Keynesian rules therefore differs substantially from the mainstream rule philosophy. Furthermore, because of the attention paid to fundamental uncertainty, Post Keynesian rules have to be interpreted as policies intended to achieve desirable goals, rather than strict rules.

\section{I.I 'Activist rules}

According to the ractivist rules proponents, the mainstream inflation targeting rule leads to flawed interest rate adjustment because it overlooks the real effects of monetary policy (see also Sawyer 2007). The innovative proposal for a (flexible opportunistic approach developed by Fontana and Palacio-Vera (2003 and 2007) seeks to encourage the growth rate of output and employment, besides stabilizing output in the short run and achieving price stability in the long run.

The standard opportunistic approach (Orphanides/Wilcox 1996) states that, in order to be able to take advantage of a possible exogenous adjustment of the inflation rate towards the long-run target, the central bank should not adjust interest rates as long as the actual inflation rate remains within some predetermined upper and lower limits around the target. By contrast, the flexible opportunistic approach puts forward that the possible long-run effects of monetary policy on potential output argue in favour of a policy loosening when the actual rate of inflation is below the target but above the predetermined lower bound. In a similar way, if the actual rate of inflation is above the target but below the predetermined upper bound, the flexible opportunistic approach states that monetary policy should moderately decrease the interest rate so as to take advantage of a possible increase in potential output, which would subsequently offset possible inflationary pressure.

Palley (2007) considers other real effects of monetary policy, besides the effects on potential output and growth, and argues that inflation targeting »biases decisions toward low inflation by obscuring the fact that policy also affects unemployment, real wages, and growth " (Palley 2007: 6I). Taking these real effects into account, Palley calls for setting the rate of interest so as to balance the possible advantages that may follow from accepting an 
increased inflation rate with the advantage of low inflation. In his model, when unemployment is sufficiently high, the only cost to monetary stimulus is increased inflation. The authorities in that case may reduce the rate of interest so that unemployment decreases towards Palley's MURI (minimum unemployment rate of inflation, beyond which further inflation increases would have a counterproductive effect on employment) ${ }^{4}$. However, a trade-off between higher wages and lower unemployment, versus higher inflation and lower growth, may arise as unemployment falls. This is because the economy, under certain conditions, ${ }^{5}$ becomes profit-led (as the profit rate is negatively affected by unemployment). This interesting feature of Palley's model suggests that the rate of interest should not be adjusted according to a rigid predetermined rule, for the economy may become wage-led or profit-led depending on the level of unemployment, which affects the terms of the tradeoff facing monetary policy.

As they seek to take advantage of the potential real effects of monetary policy, Post Keynesian ractivist، rules unquestionably improve upon the mainstream's inflation targeting،. There is however an important difficulty related to the conventional character of long-term interest rates which make their feasibility uncertain. The feasibility of these rules indeed rests on the questionable assumption that the long-term interest rate (the real rate in the case of the flexible opportunistic approach) ${ }^{6}$ can be adjusted so as to reach the ideal target. The point is that the shifting nature of the state of confidence has serious implications for the ability of monetary policy to control the long-term interest rate through operating on the overnight rate. For example, Lavoie (1999: 2), who suggests that 'monetary authorities have the ultimate say on the convention', pointed out that the spreads between the longterm rates and the overnight rate vary according to the liquidity preference of the commercial banks and the participants in the financial markets:

"As Smithin (1996: 93) puts it, a role for Keynesian liquidity preference can be retained in this scenario, in that liquidity preference considerations may well periodically insert a wedge between those rates of interest which are more or less directly under the central bank control and rates elsewhere« (Lavoie 1999: 2).

Such a difficulty may arise especially in the case of interest rate reductions. When the monetary base is increased as a result of lower short-term interest rates, lower long-term bank rates in principle boost the demand for credit. But if, at the same time, liquidity preference increases, banks may be able to sell more credit without needing to reduce their interest rates, for non-bank loan (bond) rates tend in this case to rise in order to compensate for the increasing liquidity preference.

4 This is related to the backward-bending Phillips curve of the model: as real wage resistance increases as inflation increases, the grease effect on employment, which is associated with the negative effect of inflation on real wages, erodes as inflation increases. See Palley (2007) for details.

5 If real wages do not rise too steeply as unemployment decreases, authorities may reach the MURI without encountering a growth trade-off; otherwise, there may be a trade-off between growth and pushing the unemployment rate to the MURI (Palley 2007: 74).

6 A specific problem raised by the control over the real rate is discussed below. 
Of course central banks may also intervene directly in financial markets with the aim of influencing long-term interest rates. But even if

"the monetary authority were prepared to deal both ways on specified terms in debts of all maturities, and even more so if it were prepared to deal in debts of varying degree of risk",

there would be "limitations on the ability of the monetary authority to establish any given complex of rates of interest for debts of different terms and risk " (Keynes 1936: 205 and 207). ${ }^{7}$ Some of these limitations (see Keynes 1936: 207-208 for a detailed discussion) can be considered purely theoretical, insofar as they would only arise in extreme circumstances (virtually absolute liquidity preference when rates are considered too low; breakdown of stability in the rate of interest - owing to a flight from the currency or other financial crisis); but others apply in normal circumstances (the intermediate cost of bringing the borrower and the lender together, the allowance for risk required by the lender, including liquidity risk).

\section{I.2 >Parking it rules}

Feasibility is also an issue for the >Parking it rules but in a way that differs according to the type of the rule considered. ,Parking it r rules divide into short-term nominal rate and longterm real rate rules. Let us first discuss the ,fair rate rule, understood in the spirit of Pasinetti (198I) (see also Lavoie I999), and the slow real rate proposed in Smithin (2007) (also Atesoglu/Smithin 2006, Hein/Stockhammer 2007). Both are real rate based rules and share the normative purpose of providing economic policy with an sexplicit distributional objectiver. The sfair rater rule consists in equalizing the real interest rate with the productivity growth rate, so that the rentiers' share in the national income is constant. Smithin's rule, on the other hand, holds to setting the real interest rate at a low level (a cheap money policy). The distribution effect here differs essentially because

»it does not $[\ldots]$ guarantee a share for existing wealth holders (as opposed to entrepreneurs or workers) in current productivity increases, as would the notion of the ,fair interest rate [...]. This omission might be justified on the grounds that it is the latter, rather than the former, who are actually responsible for the productivity increases" (Smithin 2007: II6).

Both rules aim at setting the real rate of interest at a target level, and both are therefore subject to the problem of feasibility. There is, however, another difficulty in this case, for the real rate of interest is not a single variable (as it would be in a barter or sneutral economy); it is the difference between the price of liquidity (the long-term nominal rate) and the expected inflation rate. Hence how could a central bank go about achieving these twin objectives with only one instrument (the overnight rate)? 
Post Keynesians reject the belief in a natural real rate of interest, and it is therefore often assumed that the determination of this variable is left to the central bank, as suggested in Smithin (1994: 172 - 173) and Lavoie (1996: 277 and 1999: 2). However the discussion of how the central bank could manage to control the long-term real interest rate is not totally convincing, for it rests on the idea that, provided the central bank is able to adjust the long-term nominal rate, it can easily adjust the nominal rate to take account of the expected inflation rate. But this requires that the expected rate of inflation is independent of the nominal rate of interest, which is not self-evidently true. Even if authorities intend to anchor expectations by committing themselves to an inflation target, the official target would not anchor expectations if agents thought the nominal interest rate was inconsistent with the target. Thus, either the central bank anchors the expected inflation but cannot set the nominal rate independently, or the central bank sets the interest rate but cannot anchor the expected inflation rate independently. In either case, the central bank can hardly be said to control the real interest rate.

Short-term nominal rate rules are not subject to such a limitation, for the short-term nominal interest rate is very closely related to the central bank's overnight rate (outside periods of crisis). The 'Kansas City` rule calls for the seuthanasia of the rentier by means of a zero short-term nominal rate (Wray 2007). ${ }^{8}$ Let us first consider Keynes's views on the issue. ' The social philosophy towards which the General Theory might lead (Keynes 1936: 374-377) focuses on our ability to manage the rate of interest so as to raise the inducement to invest to the level where, given the aggregate propensity to consume (including the State), there is full employment. Insofar as the accumulation of capital decreases the marginal efficiency of capital, a decrease in the interest rate will be necessary in the long run. That is the essence of Keynes's prediction of the euthanasia of the rentier. According to his argument, the ideal policy is not to maintain the interest rate at a low fixed level unconditionally; it is to adjust the interest rate to the level that ensures full employment, given the marginal efficiency of capital and the aggregate propensity to consume. As these variables may change in response to changes in the rate (and the state) of capital accumulation, in productivity growth or in the government's propensity to consume, among other factors, it would be imprudent to adopt a rule that could not take account of such developments.

The `Kansas City` version of the short-term nominal rate sparking it‘ rule would work as well as is possible against unemployment, but in the face of distributive tensions aimed for example at increasing the share of profits, or wages, or government revenues, it would allow for monetary accommodation of the resulting inflationary pressures. Hein and Stockhammer (2007: 17) suggest that low real interest rates rather reduce inflationary pressures and that it is, on the contrary, high interest rates that fuel inflation, based on a cost push argument. Although such a mechanism must of course be considered, notice that there are many cost push channels which could feed distribution conflict even when interest rates are low, and that in this case, the monetary accommodation induced by the sparking it $\triangleleft$ rule

8 Câmara Neto and Vernengo (2004) also advocate a low interest rate policy so as to make it easier for the government to implement a sound countercyclical fiscal policy. 
would certainly fuel inflation. It is no doubt a good thing that the central bank accommodates the banks when they need to refinance themselves as a result of the credit-money they have created in response to viable activities, but when the demand for credit-money results from the kind of distributive inflationary pressures mentioned above, ${ }^{9}$ the central bank faces a dilemma: either it accommodates inflation, so that unemployment does not rise, or it fights the distributive conflict by means of higher interest and unemployment rates. Such a dilemma has no objective solution that could be picked out from economic theory, especially if inflationary pressures are strong and threaten confidence in the purchasing power of money. It is a political decision, a matter for the community as a whole.

The dilemma would vanish if, as recommended in Setterfield (2007a, see also Hein/ Stockhammer 2007, Setterfield/Lima 2008, Rochon/Setterfield 2007a and 2007b), an incomes policy could harmonise the distribution of income. But even in that case, it is doubtful whether a zero-rate rule is really feasible, for there are events which may force the central bank to adjust the overnight rate. For example, Wray (2007) points out the problem of exchange rate stabilization in fixed peg regimes, although his discussion then abstracts from the problem by assuming flexible exchange rates. Yet such an assumption does not really solve the problem, especially in the case of a large or medium country. Such a country indeed cannot really have a totally independent interest rate policy even in the case of a flexible exchange rate, for there are negative externalities, some of which pass through the exchange rate variations (as in the case of ‘competitive depreciation`), which normally trigger interest rate policy responses in foreign countries, aimed at offsetting the externalities and related exchange rate variations. ${ }^{10}$ Hence, anticipating the foreign reaction, the policy of the home country may be to set the interest rate in accordance with an racceptabler exchange rate, instead of unilaterally implementing a 'parking it` rule.

\subsection{Post Keynesian alternatives to inflation targeting: Coping with feasibility}

According to Keynes, writing on sthe social philosophy to which the General Theory might lead`, the ideal policy is to adjust the interest rate to the level which ensures full employment, given the marginal efficiency of capital and the aggregate propensity to consume. It is the merit of those Post Keynesian rules discussed above that they reintroduce the philosophical dimension into the theoretical debate on economic policy. It is a positive contribution of the sparking it a approach, to question, in normative terms, the role of monetary policy on the grounds of income distribution. It is a positive contribution of the ractivists to emphasise the inadequacy of inflation targeting in terms of the long-run effects of mon-

9 As suggested in Section 2, inflationary distributive tensions develop, provided the central bank allows them, that is, when, under the central bank refinancing conditions, banks accommodate the growth in money demand resulting from the rising wage and price level.

IO This is not to say that the short-term nominal interest rate is the appropriate instrument for achieving a specific exchange rate target; it is rather to say that monetary authorities may hardly disregard the effects that short-term rates may have on the exchange rate (through their effects on long term rates, international capital flows, balance of payments...). 
etary policy on economic growth and real magnitudes, and to promote policies intended to take advantage of these effects.

Yet Post Keynesians need to identify policies that are not only based on sound social philosophy, but that are also feasible in general. The Post Keynesian monetary rules discussed above may be feasible in favourable circumstances, and it is therefore of importance to know about the ideal policy; but authorities in general have not the assured control over the long-term nominal and real rates of interest required to reach the ideal outcome. In our uncertain world, the alternative to the hydraulic inflation targeting policy of the mainstream does not hold only in designing ideal goals, but also in dealing with the difficult task of controlling interest rates effectively, in which success never is assured insofar as true uncertainty prevails.

Keynes's General Theory, especially in Chapter 13 (Section 3), Chapter I5 (Section 2), and Chapter 19 (Section 2 and 3), offers valuable insights in this matter, first by identifying the sources of the difficulty, and second by suggesting general principles for the design of monetary policy.

Two related difficulties are identified. The first one is that the equilibrium interest rate

»is a highly conventional [...] phenomenon. For its actual value is largely governed by the prevailing view as to what its value is expected to be. Any level of interest which is accepted with sufficient conviction as likely to be durable will be durable; subject, of course, in a changing society to fluctuations for all kinds of reasons round the expected normal.«(Keynes 1936: 203).

Therefore unemployment develops »because people want the moon« (Keynes 1936: 235), that is, because the long-term equilibrium interest rate is not low enough when liquidity preference is too high, given the marginal efficiency of capital and the aggregate propensity to consume. The difficult task of monetary policy is to influence the convention so that the long-term interest rate permits a higher level of employment. The second difficulty is that the volatility of confidence makes the demand for money and the inducement to invest unstable and uncertain, in the Keynesian understanding of the term, with the result that both control over the long-term interest rate and the final effect on effective demand are erratic.

The policy problem is all the more complex as short-term interest rate variations may interfere with the state of confidence, thereby producing shifts in the macroeconomic relationships, and making uncertainty endogenous to the monetary policy itself. Let us suppose that the cut in the short-term rate starts to have some effect on the long-term rate. According to Keynes's theory of interest, if the market believes the sconventional long rate is higher than the actual, it will expect a future increase, and agents will increase their liquidity-preference, thereby limiting or possibly preventing the reduction in the long-term rate. In the words of Bateman, who has opportunely recalled the special attention Keynes paid to the state of confidence and its implications for the making of economic policy, success- 
ful policies have to "take into account the unpredictable reactions of businessmen to those policies« (Bateman 2003: 82).

"Thus a monetary policy which strikes public opinion as being experimental in character or easily liable to change may fail in its objective of greatly reducing the longterm rate of interest, because $M_{2}$ may tend to increase almost without limit in response to a reduction of $r$ below a certain figure« (Keynes 1936: 203).

As regard solutions for feasible monetary policies, Keynes argued that a prudent monetary policy can take advantage of the conventional nature of the interest rate:

»if it appeals to public opinion as being reasonable and practicable and in the public interest, rooted in strong conviction, and promoted by an authority unlikely to be superseded [...]. Public opinion can be fairly rapidly accustomed to a modest fall in the rate of interest and the conventional expectation of the future may be modified accordingly; thus preparing the way for a further movement - up to a point. The fall in the long-term rate of interest in Great Britain after her departure from the gold standard provides an interesting example of this; - the major movements were effected by a series of discontinuous jumps, as the liquidity function of the public, having become accustomed to each successive reduction, became ready to respond to some new incentive in the news or in the policy of the authorities" (Keynes 1936: 203-204).

Control over the long-term interest rate therefore requires that the central bank can drive the market's view of the future, which is the essential Post Keynesian transmission channel of monetary policy. But the path may be narrow. If the central bank acts to decrease the long-term interest rate gradually, the expected reductions may have a negative impact on the marginal efficiency of capital ${ }^{\mathrm{II}}$ and if, on the other hand, the central bank attempts a sharp adjustment in the long-term interest rate, liquidity preference may rise and the marginal efficiency of capital may decrease through an adverse effect on confidence ${ }^{\mathrm{r}}$. Hence, there are conditions for the success of a monetary policy, the study of which would shed some light on the design of monetary policy from the Post Keynesian point of view. But we have to bear in mind that macroeconomic policy in the presence of uncertainty is necessarily context-dependent and, therefore, discretionary, meaning that policy-makers cannot commit themselves to specific targets ${ }^{13}$, although they can express ideal objectives. The

II This is a second-order argument, where the expectation that future investment will be content with a lower yield (because of the expected falls in the future rate of interest) depresses the prospective yield of current investment (Keynes 1936: 143). The argument is also developed in relation to expected money-wage decreases in Keynes (1936: 263), where monetary policy also is considered.

I2 "Just as a moderate increase in the quantity of money may exert an inadequate influence over the long-term rate of interest, whilst an immoderate increase may offset its other advantages by its disturbing effect on confidence» (Keynes 1936: 266-267).

I3 The term sdiscretionary is in contrast to a commitment to some automatic rule. Hence, our argument actually echoes Bateman's (2003) observation that Keynes rejected the old hydraulic version 
required future responses of policy instruments cannot be encapsulated in a simple - or even a complex - rule.

\section{Conclusion}

If economic systems were soptimizable in the manner postulated by mainstream economic policy, it would be unlikely that Post Keynesians could improve upon the policy of inflation targeting. But, as the world is uncertain, there is scope for genuine Post Keynesian economic policy to offer superior performance in the real world.

The recent Post Keynesian reflection on economic policy has produced a variety of alternatives to inflation targeting. Although they are not mutually consistent, they share a consensus about the social philosophy underpinning the theoretical debate on economic policy, about the normative role of monetary policy in the sphere of income distribution, and about the effects of monetary policy on long-run economic growth and real magnitudes. They also suggest policy principles which may prove to be useful in favourable circumstances.

However, the proposed alternative interest rate rules, especially the 'parking it or sactivist rules based on the long-term rate, come up against the question of feasibility. A generic difficulty is that central banks do not have perfect control of the long-term rate of interest, so that they may be unable to implement any long-term interest rate rule. This is a consequence of the instability of the demand for money and in turn, of strong uncertainty. The zero short-term interest rate rule, on the other hand, seems to be technically feasible but it can hardly be recommended in general, for it could produce undesirable consequences on inflation (unless an income policy effectively suppresses distributive conflicts) and exchange rates.

The challenge for Post Keynesians is therefore to provide principles for the conduct of economic policy in a system without any natural anchor and subject to unpredictable shifts due to the volatility of the state of confidence. ${ }^{\mathrm{I}}$ This is obviously a harder task than the construction of invariable simple rules for an enchanted world, all the more so as the effects of monetary policy on aggregate demand and inflation are uncertain. Yet there is no way out: central banks and governments have the uncomfortable duty of managing an unruly economy, despite the absence of any snaturak way or optimal rule for doing so.

The success of such policies rests on their ability to move the long-term expectations and related conventional interest rate into line with a feasible employment target. The mainstream concept of policy credibility is irrelevant here. In the face of uncertainty, it makes little sense to wonder whether the authorities will, or will not, honour their commitment to an unfeasible ideal target. The question is whether the authorities are pursuing feasible objectives that have been pragmatically defined in accordance with circumstances, and

of discretionary policies (not discretionary policies in general).

I4 A first formal attempt is suggested in Asensio (2006 and 2007a). 
whether these objectives have been widely understood and accepted. It is a matter of confidence, rather than credibility. ${ }^{15}$ Pushing the conventional interest rate, cautiously, as close as possible to the level consistent with full employment in an uncertain world is quite different from stabilizing the economy around its `natural position in a fundamentally stable system. We can surely claim that those who once made accusations against a hydraulic approach to policy must now themselves stand so accused.

\section{References}

Arestis, P., Sawyer, M. (2003a): On the effectiveness of monetary policy and fiscal policy, Levy Economics Institute of Bard College Working Paper, No. 369.

Arestis, P., Sawyer, M. (2003b): Reinventing fiscal policy, in: Journal of Post Keynesian Economics, 26, 3-25.

Arestis, P., Sawyer, M. (2003c): The case for fiscal policy, Levy Economics Institute of Bard College Working Paper, No. 382.

Asensio, A. (2006): New-Consensus macroeconomic governance in a Keynesian world, and the Keynesian alternative, in: Brazilian Journal of Political Economy, 26, 537 - 551.

Asensio, A. (2007a): Inflation targeting drawbacks in the absence of a natural anchor: A Keynesian appraisal of the Fed and ECB policies over the period $1999-2006,3^{\text {rd }}$ bi-annual conference of the CEMF: Post Keynesian Principles of Economic Policy, Dijon (France): University of Burgundy, December 2007.

Asensio, A. (2007b): Monetary and budgetary-fiscal policy interactions in a Keynesian context: Revisiting macroeconomic governance, in: Arestis P., Hein, E., Le Héron, E. (eds.), Aspects of Modern Macroeconomic and Monetary Policies, London: Palgrave Macmillan, $80-105$.

Atesoglu, H.S. (2007): The neutral rate of interest and a new monetary policy rule, in: Journal of Post Keynesian Economics, 29, 689- 697.

Atesoglu, H.S., Smithin, J. (2006): Inflation targeting in a simple macroeconomic model, in: Journal of Post Keynesian Economics, 28, 673-688.

Bateman, B.W. (2003): The end of Keynes and philosophy?, in: Runde, J., Mizuhara, S. (eds.), The Philosophy of Keynes's Economics: Probability, Uncertainty, and Convention, London and New York: Routledge, $7 \mathrm{I}-84$.

Benassy, J.P. (2007): IS-LM and the multiplier: A dynamic general equilibrium model, in: Economic Letters, 96, I89- 195.

Câmara Neto, A.F., Vernengo, M. (2004): Fiscal policy and the Washington consensus: A Post Keynesian perspective, in: Journal of Post Keynesian Economics, 27, 333-343.

Davidson, P. (2006): Can, or should, a central bank inflation target?, in: Journal of Post Keynesian Economics, 28, 689-703.

I5 See Le Héron (2006 and 2007) for an analysis of Greenspan's strategy in terms of confidence versus credibility. 
Dixit, A., Lambertini, L. (2003): Symbiosis of monetary and fiscal policies in a monetary union, in: Journal of International Economics, 6o, 235- 247.

Fisher, I. (1933): The debt deflation theory of great depression, in: Econometrica, I(4), $337-357$.

Fontana, G., Palacio-Vera, A. (2003): Is there an active role for monetary policy in the endogenous money approach?, in: Journal of Economic Issues, 37, 5II - 517.

Fontana, G., Palacio-Vera, A. (2007): Are long-run price stability and short-run output stabilization all that monetary policy can aim for?, in: Metroeconomica, 58, 269-298.

Hein, E., Stockhammer, E. (2007): Macroeconomic policy mix, employment and inflation in a Post-Keynesian alternative to the New Consensus Model, Macroeconomic Policy Institute (IMK) Working Paper, No. Io/2007.

Keynes, J.M. (1936): The General Theory of Employment, Interest and Money, London: Macmillan.

Lavoie, Marc (1996): Horizontalism, structuralism, liquidity preference and the principle of increasing risk, in: Scottish Journal of Political Economy, 43, 275-300.

Lavoie, M. (I999): Fair rates of interest in Post-Keynesian political economy, University of Ottawa, URL: http://aixi.uottawa.ca/ robinson/english/wp/fairratecla.pdf.

Le Héron, E. (2006): Alan Greenspan, the confidence strategy, in: Brazilian Journal of Political Economy, 26, 502 - 517.

Le Héron, E. (2007): The new governance in monetary policy: A critical appraisal of the Fed and the ECB, in: Arestis, P., Hein, E., Le Héron, E. (eds.), Aspects of Modern Monetary and Macroeconomic Policies, London: Palgrave Macmillan, I46 - I7I.

Orphanides, A., Wilcox, D.W. (1996): The Opportunistic Approach to Disinflation, Washington, D.C.: Board of Governors of the Federal Reserve System.

Palley, T.I. (1996): The institutionalization of deflationary policy bias, Economies et Sociétés, séries MP, IO, $247-268$.

Palley, T.I. (200I): The role of institutions and policies in creating high European unemployment: The evidence, Levy Institute Working Paper, No. 336.

Palley, T.I. (2006): A Post Keynesian framework for monetary policy: Why interest rate operating procedures are not enough, in: Gnos, C., Rochon, L.P. (eds.), Post Keynesian Principles of Economic Policy, Cheltenham: Edward Elgar, $78-98$.

Palley, T.I. (2007): Macroeconomics and monetary policy: Competing theoretical frameworks, in: Journal of Post Keynesian Economics, 30, 6I - 78.

Pasinetti, L. (198I): Structural Change and Economic Growth, Cambridge: Cambridge University Press.

Rochon, L.P., Setterfield, M. (2007a): Interest rates, income distribution, and monetary policy dominance: Post Keynesians and the "fair rate« of interest, in: Journal of Post Keynesian Economics, 30, $13-42$.

Rochon, L.P., Setterfield, M. (2007b): Post Keynesian interest rate rules and macroeconomic performance: A comparative evaluation, paper presented at the Eastern Economic Association Conference, New York, February 2007. 
Sawyer, M. (2007): Seeking to reformulate macroeconomic policies, 3rd bi-annual conference of the CEMF: Post Keynesian Principles of Economic Policy, Dijon (France): University of Burgundy, December 2007.

Setterfield, M. (2007a): Is inflation targeting inicial to employment?, University of Vermont conference paper, URL: http://www.uvm.edu/_econ/keynesian_conf/SetterfieldI_ paper.pdf.

Setterfield, M. (2007b): Is there a stabilizing role for fiscal policy in the New Consensus?, in: Review of Political Economy, 19, 405-418.

Setterfield, M., Lima, G.T. (2008): Inflation targeting and macroeconomic stability in a Post Keynesian economy, in: Journal of Post Keynesian Economics, 30, 435 - 46I.

Smithin, J. (1994), Controversies in Monetary Economics, Aldershot: Edward Elgar.

Smithin, J. (1996): Macroeconomic Policy and the Future of Capitalism: The Revenge of the Rentiers and the Threat to Prosperity, Aldershot: Edward Elgar.

Smithin, J. (2007): A real interest rate rule for monetary policy?, in: Journal of Post Keynesian Economics, 30, IOI - II8.

Tily, G. (2006): Keynes's theory of liquidity preference and his debt management and monetary policies, in: Cambridge Journal of Economics, 30, $657-670$.

Wray, R. (2007): A Post Keynesian view of central bank independence, policy targets, and the rules versus discretion debate, in: Journal of Post Keynesian Economics, 30, II9 - I4I. 
